\title{
Thermophysical Measurements on 90Ti-6Al-4V Alloy Above 1450 K Using a Transient (Subsecond) Technique*
}

\author{
A. Cezairliyan, J. L. McClure, and R. Taylor** \\ Institute for Materials Research, National Bureau of Standards, Washington, D.C. 20234
}

(March 5, 1977)

\begin{abstract}
Simultaneous measurements are described of specific heat capacity, electrical resistivity and hemispherical total emittance of the ternary alloy $90 \mathrm{Ti}-\mathrm{Al}-4 \mathrm{~V}$ in the temperature range 1450 to $1900 \mathrm{~K}$, and the melting point and and the radiance temperature at the melting point of the alloy by a subsecond duration transient technique. The results are expressed by the relations:

$$
\begin{aligned}
c_{p} & =1.3833-9.943 \times 10^{-4} T+3.745 \times 10^{-7} T^{2} \\
\rho & =152.65+1.9304 \times 10^{-2} T-3.9548 \times 10^{-6} T^{2}
\end{aligned}
$$

where $c_{p}$ is in $\mathrm{J} \cdot \mathrm{g}^{-1} \cdot \mathrm{K}^{-1}, \rho$ is in $\mu \Omega \cdot \mathrm{cm}$, and $T$ is in $\mathrm{K}$. The value of the hemispherical total emittance is 0.39 in the range 1700 to $1900 \mathrm{~K}$. The melting point and the radiance temperature at the melting point are 1943 and 1796 total emittance of the ternary alloy $90 \mathrm{Ti}-6 \mathrm{Al}-4 \mathrm{~V}$ in the temperature range 1450 to $1900 \mathrm{~K}$, and the melting point 0.395. Estimated inaccuracies of measured properties are: 3 percent for specific heat capacity, 1 percent for electrical resistivity, 5 percent for hemispherical total emittance and $8 \mathrm{~K}$ for melting point and radiance temperature at the melting point.
\end{abstract}

Key words: Electrical resistivity; heat capacity; high-speed measurements; high temperatures; melting; normal spectral emittance; radiance temperature; specific heat capacity; thermal radiation properties; thermodynamics; titanium alloy.

\section{Introduction}

In this paper, application of a transient technique to the measurement of selected thermophysical properties (specific heat capacity, electrical resistivity, hemispherical total emittance, melting point, ${ }^{1}$ radiance temperature ${ }^{2}$ at the melting point) of the alloy $90 \mathrm{Ti}-6 \mathrm{Al}-4 \mathrm{~V}$ above $1450 \mathrm{~K}$ is described.

The method is based on rapid resistive self-heating of the specimen from room temperature to its melting point in less than one second by the passage of an electrical current pulse through it; and on measuring, with millisecond resolution, such experimental quantities as current through the specimen, potential drop across the specimen, and specimen temperature. Detailes regarding the construction and operation of the measurement system, the formulation of relations for properties, the methods of measuring experimental quantities, and other pertinent information are given in earlier publications $[1,2]^{3}$.

\section{Measurements}

\subsection{Specimens}

The measurements of specific heat capacity, electrical resistivity, hemispherical total emittance, and melting point

* This work was supported in part by the U. S. Air Force Office of Scientific Research.

** Guest scientist from the University of Manchester Institute of Science and Technology, Manchester, United Kingdom.

Alloys have a melting range instead of a melting point, however for convenience, in the present work the solidus point of the alloy is referred to as the melting point.

${ }^{2}$ Radiance temperature (sometimes referred to as brightness temperature) is the apparent temperture of the specimen surface as measured by the pyrometer.

${ }^{3}$ Figures in brackets indicate the literature references at the end of this paper.
. were performed on four specimens in the form of tubes. The tubes were fabricated from rods by removing the center portion using an electro-erosion technique. The nominal dimensions of the specimens were: length: $76.2 \mathrm{~mm}$; outside diameter, $6.3 \mathrm{~mm}$; and wall thickness, $0.5 \mathrm{~mm}$. A small rectangular hole $(0.5 \times 1 \mathrm{~mm})$ fabricated in the wall at the middle of the specimen approximated blackbody conditions for optical temperature measurements. The outer surfaces of the specimens were polished to reduce heat loss due to thermal radiation.

The radiance temperature measurements at the melting point were performed on specimens in the form of strips fabricated from a plate. The nominal dimensions of the strips were: length, $51 \mathrm{~mm}$; width, $4.7 \mathrm{~mm}$, and thickness, 0.25 $\mathrm{mm}$. Before the experiments, the surface of the specimens was treated using abrasive; three different grades of abrasive were used yielding three different surface roughnesses (ranging from approximately 0.4 to $0.9 \mu \mathrm{m}$ RMS) for different specimens.

The specimen material in rod and plate form was furnished by the U. S. Air Force Materials Laboratory, Wright Patterson Air Force Base, Ohio, and comprised two different lots of material. Chemical analyses of the material which are listed in table 1, show slight differences in composition. The rod material, from which the tube-shape specimens were fabricated, was hot swaged and the structure was composed of primary alpha titanium together with some acicular alpha + retained beta. The plate material, from which strip-shape specimens were fabricated, showed evidence of an elongated grain structure comprising primary alpha and beta. Photomicrographs of the two structures are shown in figure 1. 
TABLE 1. Composition of the titanium alloy ${ }^{a}$

\begin{tabular}{c|c|c|c|c|c|c|c|c|c|c|c|c|c|c|c|c|c|c|c|c|c|c|c}
\hline \hline \multirow{2}{*}{$\begin{array}{c}\text { Material } \\
\quad \text { Form }\end{array}$} & \multicolumn{1}{|c|}{ in wt. \% } & $\mathrm{Al}$ & $\mathrm{V}$ & $\mathrm{B}$ & $\mathrm{Ca}$ & $\mathrm{Cr}$ & $\mathrm{Cu}$ & $\mathrm{Fe}$ & $\mathrm{Mg}$ & $\mathrm{Mn}$ & $\mathrm{Mo}$ & $\mathrm{Ni}$ & $\mathrm{Nb}$ & $\mathrm{Pb}$ & $\mathrm{Si}$ & $\mathrm{Sn}$ & $\mathrm{Ta}$ & $\mathrm{W}$ & $\mathrm{Zr}$ & $\mathrm{C}$ & $\mathrm{H}$ & $\mathrm{N}$ & $\mathrm{O}$ \\
\hline Rod & 89.2 & 6.1 & 4.2 & 10 & 50 & 15 & 30 & 1500 & 50 & 30 & 150 & 15 & - & 50 & 300 & 300 & 100 & 50 & 30 & 220 & 80 & 120 & 1700 \\
Plate & 89.2 & 6.1 & 4.2 & 30 & 150 & 30 & 80 & 1500 & 30 & 60 & 80 & 30 & 100 & 15 & 80 & 80 & 100 & 15 & 30 & 390 & 30 & 90 & 1500 \\
\hline
\end{tabular}

${ }^{a}$ Information was furnished by Dr. S. R. Lyon of the U. S. Air Force Materials Laboratory.

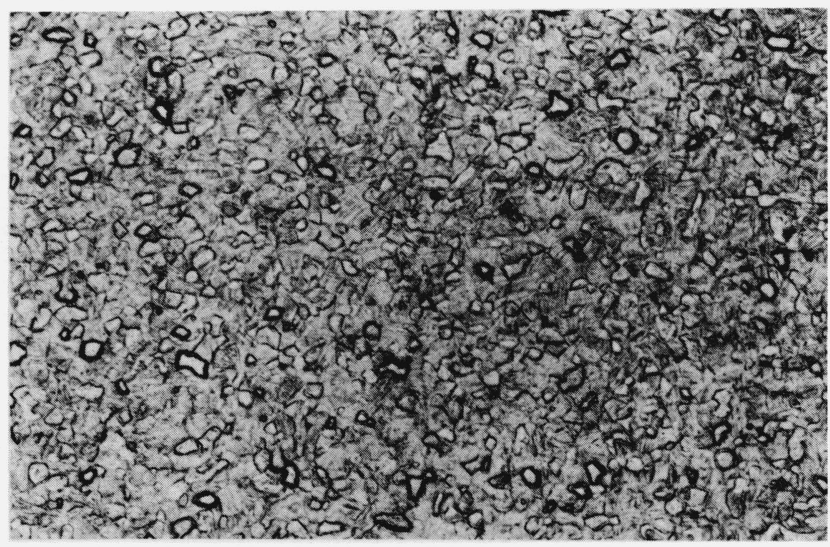

$\leftarrow 0.1 \mathrm{~mm} \rightarrow$

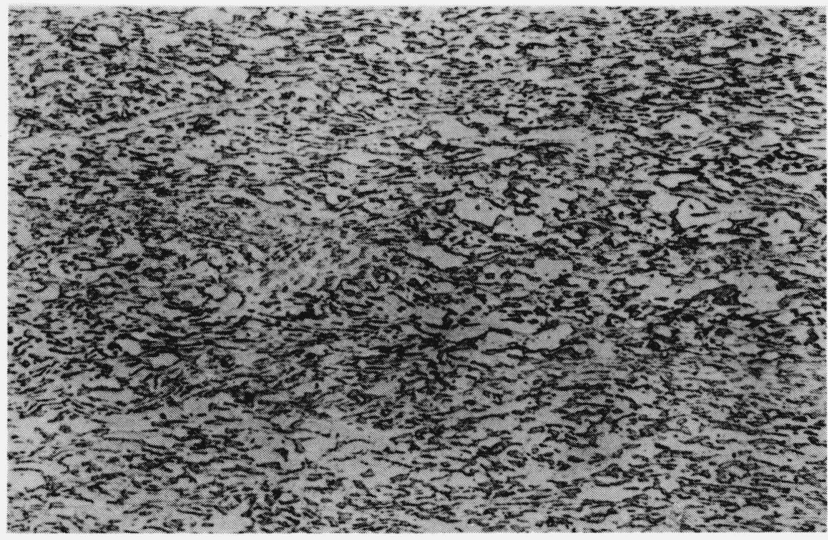

FIGURE 1. Photomicrographs of titanium alloy specimens: tube-shape (upper photograph), and strip-shape (lower photograph), obtained before the experiments.

\subsection{Procedure}

All the experiments were performed with the specimen in an argon environment at atmospheric pressure. To optimize the operation of the high-speed pyrometer, the temperature interval (1450 to $1943 \mathrm{~K}$ ) was divided into three ranges. This yielded a total of twelve experiments on four tube-shape specimens. Duration of the current pulses in experiments on tube-shape specimens ranged from 400 to $500 \mathrm{~ms}$, with heating rates ranging from 2600 to $3800 \mathrm{~K} \cdot \mathrm{s}^{-1}$. Duration of the current pulses in experiments on strip-shape specimens ranged from 400 to $800 \mathrm{~ms}$, with heating rates ranging from 1300 to $2200 \mathrm{~K} \cdot \mathrm{s}^{-1}$. Radiative heat loss from the tube-shape specimens was, in all cases, less than 2 percent at $1500 \mathrm{~K}$ and less than 5 percent at $1900 \mathrm{~K}$ of the input power.
At low temperatures and at vanadium contents greater than 3 percent, the equilibrium structure of this alloy comprises a mixture of the alpha and beta phases, although the actual structure will depend upon the heat treatment conditions. Above about $1300 \mathrm{~K}$, the exact temperature depending upon composition, the alloy transforms to wholly beta. To ensure that the transformation was completed below $1450 \mathrm{~K}$ an additional experiment was performed in which the electrical resistance of a tube-shape specimen was measured during its heating from room temperature to the melting point (in 480 $\mathrm{ms})$. The results, as shown in figure 2 indicate that the transformation occurred over a wide temperature range and that it was completed at about $1400 \mathrm{~K}$, which is below the range of the results on thermophysical properties obtained in the present investigation.

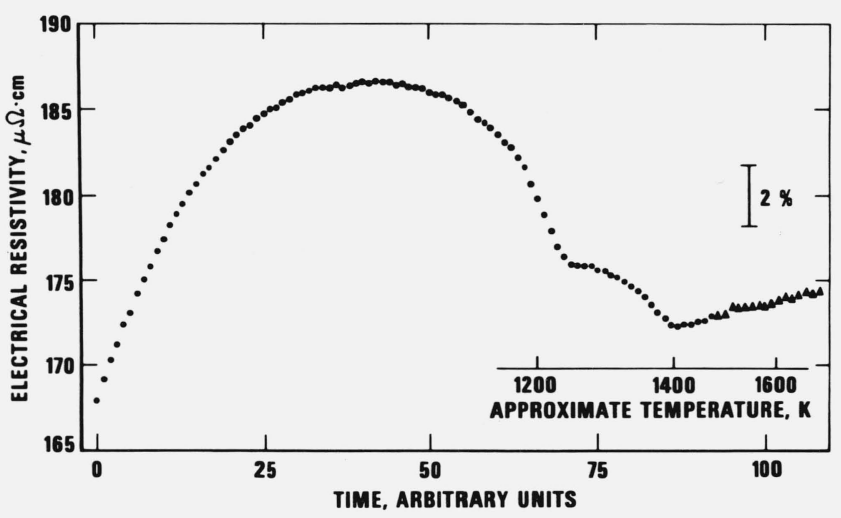

FIGURE 2. Variation of the electrical resistivity of the titanium alloy (specimen-2) as a function of time during its heating from near room temperature to $1700 \mathrm{~K}$ (1 time unit $=5 \mathrm{~ms})$.

The plotted points are the results of two consecutive experiments (dots: near room temperature to $1450 \mathrm{~K}$, and triangles: 1450 to $1700 \mathrm{~K}$ ). An approximate temperature scale (non-linear) is shown for the latter part of the heating.

\section{Results}

The thermophysical properties reported in this paper are based on the International Practical Temperature Scale of 1968 [3]. In all computations, the geometrical quantities are based on their room temperature $(298 \mathrm{~K})$ dimensions. The experimental results on specific heat capacity and electrical resistivity are represented by polynomial functions in temperature obtained by least squares approximation of the individual points. The final values on these properties, at 50 degree temperature intervals, computed using the functions are presented in table 2. The results obtained from individual experiments are given in the Appendix.

Specific Heat Capacity: Specific heat capacity was computed from data taken during the heating period. A correction 
TABLE 2. Specific heat capacity and electrical resistivity of the titanium alloy

\begin{tabular}{c|c|c}
\hline \hline \begin{tabular}{c|c}
$c_{p}$ \\
$(\mathrm{~K})$
\end{tabular} & $\begin{array}{c}\rho \\
\left(\mathrm{J} \cdot \mathrm{g}^{-1} \cdot \mathrm{K}^{-1}\right)\end{array}$ & 172.3 \\
\hline 1450 & 0.729 & 172.7 \\
1500 & .734 & 173.1 \\
1550 & .742 & 173.4 \\
1600 & .751 & 173.7 \\
1650 & .762 & 174.0 \\
1700 & .775 & 174.3 \\
1750 & .790 & 174.6 \\
1800 & .807 & 174.8 \\
1850 & .826 & 175.1 \\
1900 & .846 & \\
\hline
\end{tabular}

for power loss due to thermal radiation was made using the results on hemispherical total emittance. The function for specific heat capacity (standard deviation $=0.7 \%$ ) that represents the results in the temperature range 1450 to 1900 $\mathrm{K}$ is:

$$
c_{p}=1.3833-9.943 \times 10^{-4} T+3.745 \times 10^{-7} T^{2}
$$

where $T$ is in $\mathrm{K}$, and $c_{p}$ is in $\mathrm{J} \cdot \mathrm{g}^{-1} \cdot \mathrm{K}^{-1}$.

Electrical Resistivity: The electrical resistivity was determined from the same experiments that were used to calculate specific heat capacity. The function for electrical resistivity (standard deviation $=0.2 \%$ ) that represents the results in the temperature range 1450 to $1900 \mathrm{~K}$ is:

$\rho=152.65+1.9304 \times 10^{-2} T-3.9548 \times 10^{-6} T^{2}$

where $T$ is in $\mathrm{K}$ and $\rho$ is in $\mu \Omega \cdot \mathrm{cm}$. In the computations of the specimen's cross-sectional area, which is needed for the computations of electrical resistivity, the density of the specimen was taken as $4.422 \mathrm{~g} \cdot \mathrm{cm}^{-3}$. The measurement, before the pulse experiments, of the electrical resistivity of the four tube-shape specimens at $293 \mathrm{~K}$ with a Kelvin bridge yielded an average value of $166.2 \mu \Omega \cdot \mathrm{cm}$ with an average absolute deviation of 0.1 percent and a maximum absolute deviation of 0.2 percent.

Hemispherical Total Emittance: Hemispherical total emittance was computed using data taken during both heating and initial free radiative cooling periods. The results of measurements in the temperature range 1700 to $1900 \mathrm{~K}$ did not show any significant variation in emittance. A value of 0.39 was obtained by averaging all the results (standard deviation $=$ $2 \%$ ).

Melting Point: Temperature of the tube-shape specimens was measured near and during the initial melting period until the specimen collapsed. A plateau in temperature indicated the transition from solid to liquid phase. Typical results for the variation of the specimen temperature during melting are shown in figure 3 . The melting point for each specimen was obtained by averaging the temperature points on the plateau.

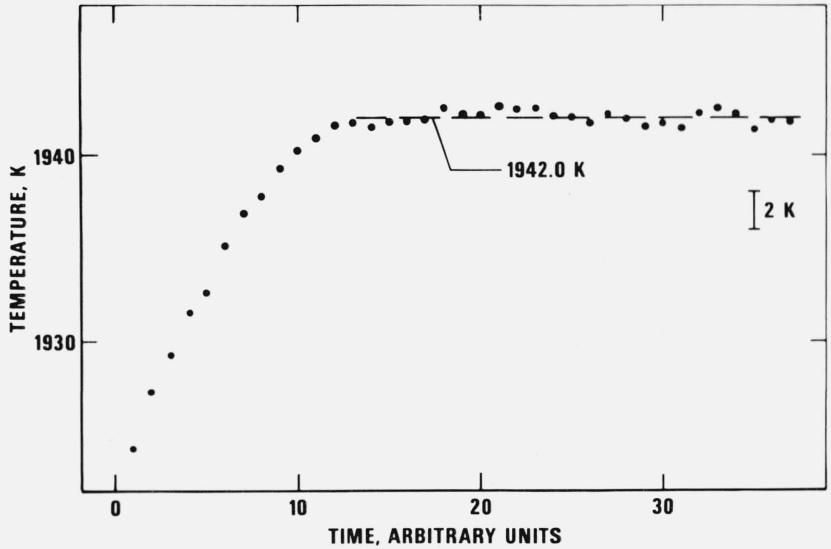

FigURE 3. Variation of the temperature of the titanium alloy (specimen-3) as a function of time near and at its melting point (1 time unit $=0.833 \mathrm{~ms}$ ).

The results are presented in table 3 . The average melting point of the four specimens is $1942.6 \mathrm{~K}$ with an average absolute deviation from the mean of $0.4 \mathrm{~K}$ and a maximum absolute deviation of $0.8 \mathrm{~K}$. It may be concluded that the melting point of the titanium alloy measured in this work is $1943 \mathrm{~K}$

TABLE 3. Summary of measurements of the melting point of the titanium alloy

\begin{tabular}{c|c|c|c}
\hline \hline $\begin{array}{c}\text { Specimen } \\
\text { number }\end{array}$ & $\begin{array}{c}\text { Number of } \\
\text { temperatures } \\
\text { at plateau }\end{array}$ & $\begin{array}{c}\text { Melting point } \\
(\mathrm{K})\end{array}$ & $\begin{array}{c}\text { Standard } \\
\text { deviation } \\
(\mathrm{K})\end{array}$ \\
\hline 1 & 10 & 1942.7 & 0.4 \\
2 & 23 & 1943.5 & .6 \\
3 & 25 & 1942.0 & .3 \\
4 & 15 & 1942.4 & .2 \\
\hline
\end{tabular}

Radiance Temperature at the Melting Point: Radiance temperature measurements were performed on the strip-shape specimens at $653 \mathrm{~nm}$ which corresponds to the effective wavelength of the pyrometer's interference filter. The bandwidth of the filter was $10 \mathrm{~nm}$. The circular area viewed by the pyrometer was $0.2 \mathrm{~mm}$ in diameter. Typical results for the variation of the specimen radiance temperature during melting are shown in figure 4 . A single value for the radiance temperature at the plateau was obtained by averaging the temperatures at the plateau. The results are presented in table 4 . The average radiance temperature at the melting point for the specimens is $1795.6 \mathrm{~K}$ with an average absolute deviation of $0.2 \mathrm{~K}$ and a maximum absolute deviation of 0.4 $\mathrm{K}$. It may be concluded that the radiance temperature of the titanium alloy measured in this work is $1796 \mathrm{~K}$.

Normal Spectral Emittance: The normal spectral emittance at the melting point was determined using the results of the radiance temperature (obtained from the measurements on strip-shape specimens) and the melting point (obtained from the measurements on tube-shape specimens). The results yield a value of 0.395 for the normal spectral emittance (at $653 \mathrm{~nm}$ ) at the melting point of the alloy. 


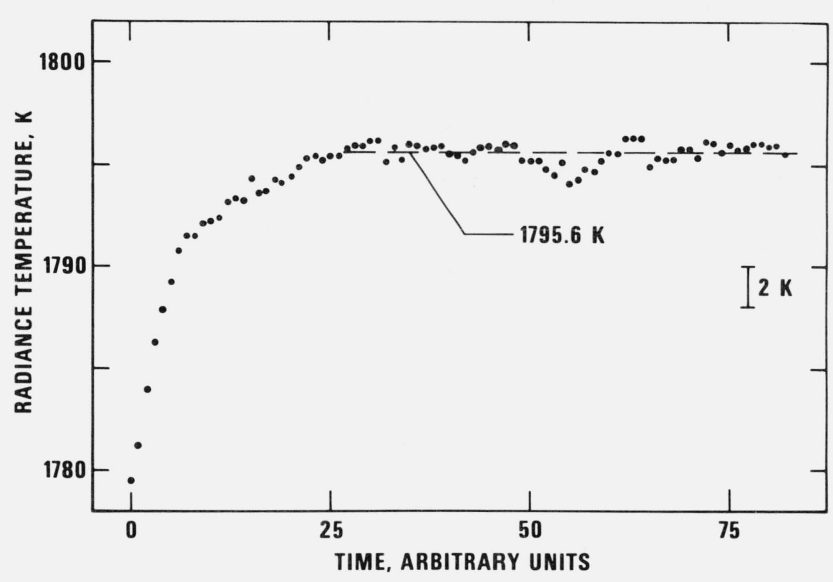

FIGURE 4. Variation of the radiance temperature (at $653 \mathrm{~nm}$ ) of the titanium alloy (specimen-2) as a function of time near and at its melting point (1 time unit $=0.833 \mathrm{~ms}$ ).

TABLE 4. Summary of measurements of the radiance temperature (at 653 $\mathrm{nm}$ ) of the titanium alloy during melting

\begin{tabular}{c|c|c|c|c}
\hline \hline $\begin{array}{c}\text { Specimen } \\
\text { number }\end{array}$ & $\begin{array}{c}\text { Typical sur- } \\
\text { face } \\
\text { Roughness } \\
(\mu \mathrm{m})\end{array}$ & $\begin{array}{c}\text { Number of tem- } \\
\text { peratures at } \\
\text { plateau }\end{array}$ & $\begin{array}{c}\text { Radiance tem- } \\
\text { perature (K) }\end{array}$ & $\begin{array}{c}\text { Standard } \\
\text { deviation } \\
(\mathrm{K})\end{array}$ \\
\hline 1 & 0.4 & 27 & 1795.4 & 0.2 \\
2 & .5 & 56 & 1795.6 & .5 \\
3 & .5 & 64 & 1795.2 & .3 \\
4 & .4 & 36 & 1795.8 & .4 \\
5 & .9 & 43 & 1795.9 & .3 \\
\hline
\end{tabular}

Estimate of Errors: The details of estimating errors in measured and computed quantities using the present measurement system are given in an earlier publication [2]. In this paper, the specific items were recomputed whenever the present conditions differed from those in the earlier publication. The results are summarized in table 5 .

TABLE 5. Estimate of errors

\begin{tabular}{l|c|c}
\hline \multicolumn{1}{c|}{ Quantity } & Imprecision $^{a}$ & Inaccuracy $^{b}$ \\
\hline Specific heat capacity & $0.7 \%$ & $3 \%$ \\
Electrical resistivity & $0.2 \%$ & $1 \%$ \\
Hemispherical total emittance & $2 \%$ & $5 \%$ \\
Melting point & $0.6 \mathrm{~K}$ & $8 \mathrm{~K}$ \\
$\begin{array}{l}\text { Radiance temperature (at melt- } \\
\text { ing point) }\end{array}$ & $0.5 \mathrm{~K}$ & $8 \mathrm{~K}$ \\
$\begin{array}{c}\text { Normal spectral emittance (at } \\
\text { melting point) }\end{array}$ & - & $3 \%$
\end{tabular}

${ }^{a}$ Imprecision refers to the standard deviation of a quantity as computed from the difference between measured value and that from the smooth function obtained by the least squares method.

${ }^{b}$ Inaccuracy refers to the estimated total error (random and systematic).

\section{Discussion}

Considering the wealth of literature data on 90Ti-6Al-4V there is remarkably little information on the physical properties of this alloy and data at temperatures above $1000 \mathrm{~K}$ does not appear to have been obtained. In figures 5 and 6 the smoothed values for specific heat capacity and electrical resistivity listed in table 2 are plotted together with the limited amount of low temperature data available in the literature. From figure 5, it can be seen that the specific heat capacity data of Ziegler and Mullins [4] may be reasonably extrapolated to join up with the present data.

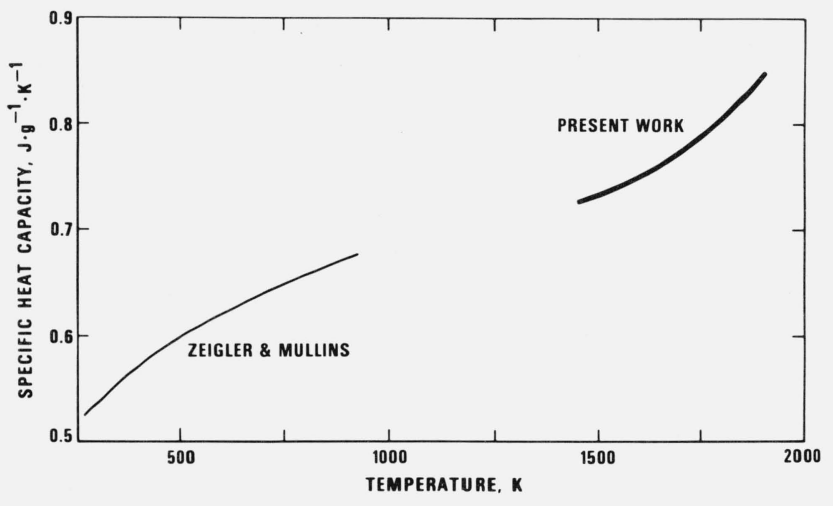

FIGURE 5. Specific heat capacity of titanium alloy reported in the literature. The alloy used by Zeigler and Mullins [4] contained 5.9 percent Al and 3.9 percent $\boldsymbol{V}$.

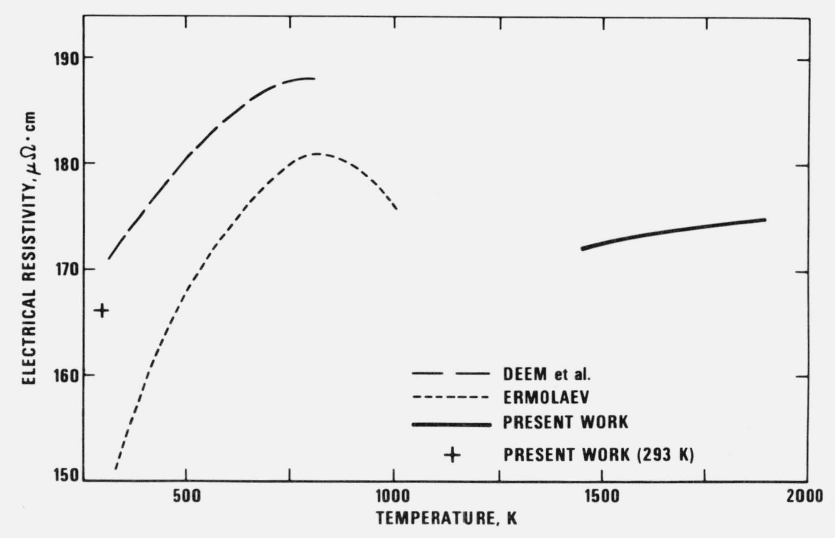

FIGURE 6. Electrical resistivity of titanium alloy reported in the literature. The alloy used by Deem et al. [5] contained 6 percent Al and 4 percent V, while that used by Ermolaev [6] contained 5 percent Al and 4 percent $V$.

The electrical resistivity data on $90 \mathrm{Ti}-6 \mathrm{Al}-4 \mathrm{~V}$ reported by Deem et al. [5] covers the temperaiure range 310 to $810 \mathrm{~K}$ and shows evidence of a maximum around $800 \mathrm{~K}$. Ermolaev [6] has measured the electrical resistivity of a titanium alloy containing 5 percent $\mathrm{Al}$ and 4 percent $\mathrm{V}$ up to $1000 \mathrm{~K}$ and his results are some 4 to 12 percent lower than the data of Deem et al. However, a definite maximum is observed around 800 
K. These results, together with those of the present work, are presented in figure 6 . The room temperature value obtained in the present work is about 2.5 percent below the value of Deem et al., but such a difference can be accounted for by variations in specimen structure. If figure 6 is inspected together with figure 2 then it is apparent that low temperature resistivity values follow the trend indicated by Deem et al. and Ermolaev, namely that resistivity increases to a maximum and then decreases. The data of the present work indicate that electrical resistivity decreases until $1250 \mathrm{~K}$ where the curve shows a kink but still decreases until $1400 \mathrm{~K}$ above which resistivity begins to increase steadily up to $1900 \mathrm{~K}$. Above $1400 \mathrm{~K}$, the resistivity results pertain to the beta phase. Below $1400 \mathrm{~K}$ however, a number of solid state reactions may be occurring, chief of which are the reactions whereby alpha prime decomposes to alpha + beta and, at high temperatures, alpha will decompose to beta. Additionally, beta is metastable at low temperatures and will itself decompose to alpha. Since these are kinetic processes affected by the heating rate, it is difficult to predict the behavior of this alloy unless further work is done involving the heating of alloys carefully heat treated to produce different structures.

No data have been found in the literature on the hemispherical total emittance of the alloy 90Ti-6Al-4V that correspond to the specimen conditions and the temperature range of the measurements of the present work. The value of the hemispherical total emittance for a similar alloy at the highest reported temperature (about $1200 \mathrm{~K}$ ) in the literature [7] is 0.47 which corresponds to a specimen with a rough surface. This high value compared to 0.39 (the value of the present work) may be attributed primarily to the differences in the specimen surface conditions.

Measurements of the normal spectral emittance at $665 \mathrm{~nm}$ on several titanium alloy specimens under different conditions were reported in the literature [8] for temperatures up to about $1700 \mathrm{~K}$. The reported results for the specimen and conditions that closely match those of the present work indicate a nearly linear variation of emittance with temperature in the range 1200 to $1700 \mathrm{~K}$. Extrapolation of these results to the melting point of the alloy (1943 K) yields a value of 0.369 for the normal spectral emittance, which is about 7 percent lower than the value of 0.395 obtained in the present work. This difference may not be very significant due to the fact that specimens were different and the literature results were extrapolated to the melting point.

According to a compilation on melting points [9], the results, reported by different investigators, of the melting point of pure titanium are in the range 1933 to $1953 \mathrm{~K}$. The value $1943 \mathrm{~K}$ obtained in the present work for the alloy is compatible with the above.

In the present experiments related to melting (true temperature obtained using tube-shape specimens and radiance temperature obtained using strip-shape specimens), it was not possible to follow the entire melting process because the specimen collapsed and opened the main electrical circuit prior to the completion of melting. However, good quality horizontal plateaus were obtained during the initial melting period which are more of a characteristic of pure metals.

The authors express their gratitude to M. S. Morse for his help with the electronic instrumentation.

\section{Appendix}

TABLE A-1. Experimental results on specific heat capacity of the titanium alloy

\begin{tabular}{|c|c|c|c|c|c|c|c|c|c|}
\hline \multirow[b]{2}{*}{ Range } & \multirow{2}{*}{$\begin{array}{c}\text { Temperature } \\
(\mathrm{K})\end{array}$} & \multicolumn{2}{|c|}{ Specimen-1 } & \multicolumn{2}{|c|}{ Specimen-2 } & \multicolumn{2}{|c|}{ Specimen-3 } & \multicolumn{2}{|c|}{ Specimen-4 } \\
\hline & & $\begin{array}{c}c_{p} \\
\left(\mathrm{~J} \cdot \mathrm{g}^{-1} \cdot \mathrm{K}^{-1}\right)\end{array}$ & $\begin{array}{l}\Delta c_{p}{ }^{\mathrm{a}} \\
(\%)\end{array}$ & $\begin{array}{c}c_{p} \\
\left(\mathrm{~J} \cdot \mathrm{g}^{-1} \cdot \mathrm{K}^{-1}\right)\end{array}$ & $\begin{array}{l}\Delta c_{p}{ }^{\mathrm{a}} \\
(\%)\end{array}$ & $\begin{array}{c}c_{p} \\
\left(\mathrm{~J} \cdot \mathrm{g}^{-1} \cdot \mathrm{K}^{-1}\right)\end{array}$ & $\begin{array}{l}\Delta c_{p}{ }^{\mathrm{a}} \\
(\%)\end{array}$ & $\left(\begin{array}{c}c_{p} \\
\left(J \cdot g^{-1} \cdot \mathrm{K}^{-1}\right)\end{array}\right.$ & $\begin{array}{l}\Delta c_{p}^{\mathrm{a}} \\
(\%)\end{array}$ \\
\hline I & $\begin{array}{l}1450 \\
1500 \\
1550 \\
1600 \\
1650\end{array}$ & $\begin{array}{r}0.7247 \\
.7332 \\
.7431 \\
.7550 \\
.7693\end{array}$ & $\begin{array}{l}-0.58 \\
-0.16 \\
+0.18 \\
+0.52 \\
+0.92\end{array}$ & $\begin{array}{r}0.7230 \\
.7327 \\
.7437 \\
.7556 \\
.7679 \\
\end{array}$ & $\begin{array}{l}-0.81 \\
-0.23 \\
+0.26 \\
+0.60 \\
+0.74\end{array}$ & $\begin{array}{r}0.7213 \\
.7305 \\
.7414 \\
.7544 \\
.7700\end{array}$ & $\begin{array}{l}-1.05 \\
-0.53 \\
-0.05 \\
+0.44 \\
+1.01\end{array}$ & $\begin{array}{c}0.7345 \\
.7380 \\
.7441 \\
.7540 \\
.7691 \\
\end{array}$ & $\begin{array}{l}+0.76 \\
+0.49 \\
+0.31 \\
+0.39 \\
+0.90\end{array}$ \\
\hline II & $\begin{array}{l}1650 \\
1700 \\
1750 \\
1800 \\
1850\end{array}$ & $\begin{array}{r}0.7595 \\
.7710 \\
.7862 \\
.8059 \\
.8311\end{array}$ & $\begin{array}{l}-0.36 \\
-0.55 \\
-0.50 \\
-0.12 \\
+0.68\end{array}$ & $\begin{array}{l}.7620 \\
.7733 \\
.7880 \\
.8064 \\
.8295 \\
\end{array}$ & $\begin{array}{l}-0.03 \\
-0.25 \\
-0.27 \\
-0.06 \\
+0.48\end{array}$ & $\begin{array}{l}.7619 \\
.7747 \\
.7902 \\
.8091 \\
.8320 \\
\end{array}$ & $\begin{array}{l}-0.04 \\
-0.07 \\
+0.01 \\
+0.28 \\
+0.78\end{array}$ & $\begin{array}{l}.7615 \\
.7767 \\
.7928 \\
.8100 \\
.8286\end{array}$ & $\begin{array}{l}-0.09 \\
+0.19 \\
+0.34 \\
+0.39 \\
+0.38\end{array}$ \\
\hline III & $\begin{array}{l}1700 \\
1750 \\
1800 \\
1850 \\
1900\end{array}$ & $\begin{array}{r}0.7775 \\
.7820 \\
.7952 \\
.8182 \\
.8538\end{array}$ & $\begin{array}{l}+0.29 \\
-1.04 \\
-1.47 \\
-0.89 \\
+0.92\end{array}$ & $\begin{array}{l}.7771 \\
.7858 \\
.7999 \\
.8206 \\
.8492\end{array}$ & $\begin{array}{l}+0.24 \\
-0.55 \\
-0.87 \\
-0.60 \\
+0.44\end{array}$ & $\begin{array}{l}.7820 \\
.7836 \\
.7948 \\
.8175 \\
.8557\end{array}$ & $\begin{array}{l}+0.87 \\
-0.83 \\
-1.52 \\
-0.98 \\
+1.13\end{array}$ & $\begin{array}{l}.7812 \\
.7860 \\
.7983 \\
.8197 \\
.8529\end{array}$ & $\begin{array}{l}+0.77 \\
-0.52 \\
-1.07 \\
-0.71 \\
+0.81\end{array}$ \\
\hline
\end{tabular}

${ }^{a}$ The quantity $\Delta c_{p}$ is percentage deviation of the individual results from the smooth function represented by equation (1). 
TABLE A-2. Experimental results on electrical resistivity of the titanium alloy

\begin{tabular}{|c|c|c|c|c|c|c|c|c|c|}
\hline \multirow{2}{*}{ Range } & \multirow{2}{*}{$\begin{array}{c}\text { Temperature } \\
\text { (K) }\end{array}$} & \multicolumn{2}{|c|}{ Specimen-1 } & \multicolumn{2}{|c|}{ Specimen-2 } & \multicolumn{2}{|c|}{ Specimen-3 } & \multicolumn{2}{|c|}{ Specimen-4 } \\
\hline & & $\begin{array}{c}\rho \\
(\mu \Omega \cdot \mathrm{cm})\end{array}$ & $\begin{array}{l}\Delta \rho^{\mathrm{a}} \\
(\%)\end{array}$ & $\begin{array}{c}\rho \\
(\mu \Omega \cdot \mathrm{cm})\end{array}$ & $\begin{array}{l}\Delta \rho^{\mathrm{a}} \\
(\%)\end{array}$ & $\begin{array}{c}\rho \\
(\mu \Omega \cdot \mathrm{cm})\end{array}$ & $\begin{array}{l}\Delta \rho^{\mathrm{a}} \\
(\%)\end{array}$ & $\begin{array}{c}\rho \\
(\mu \Omega \cdot \mathrm{cm})\end{array}$ & $\begin{array}{l}\Delta \rho^{\mathrm{a}} \\
(\%)\end{array}$ \\
\hline I & $\begin{array}{l}1450 \\
1500 \\
1550 \\
1600 \\
1650\end{array}$ & $\begin{array}{l}172.19 \\
172.56 \\
172.94 \\
173.32 \\
173.66\end{array}$ & $\begin{array}{l}-0.08 \\
-0.09 \\
-0.08 \\
-0.05 \\
-0.04\end{array}$ & $\begin{array}{l}172.80 \\
173.21 \\
173.57 \\
173.90 \\
174.22\end{array}$ & $\begin{array}{l}+0.27 \\
+0.29 \\
+0.29 \\
+0.28 \\
+0.28\end{array}$ & $\begin{array}{l}172.04 \\
172.37 \\
172.74 \\
173.13 \\
173.50\end{array}$ & $\begin{array}{l}-0.17 \\
-0.20 \\
-0.19 \\
-0.16 \\
-0.14\end{array}$ & $\begin{array}{l}172.31 \\
172.59 \\
173.02 \\
173.47 \\
173.77\end{array}$ & $\begin{array}{l}-0.01 \\
-0.07 \\
-0.03 \\
+0.03 \\
+0.02\end{array}$ \\
\hline II & $\begin{array}{l}1650 \\
1700 \\
1750 \\
1800 \\
1850\end{array}$ & $\begin{array}{l}173.75 \\
174.09 \\
174.41 \\
174.70 \\
175.00\end{array}$ & $\begin{array}{l}+0.01 \\
+0.03 \\
+0.05 \\
+0.06 \\
+0.10\end{array}$ & $\begin{array}{l}174.22 \\
174.54 \\
174.83 \\
175.12 \\
175.45\end{array}$ & $\begin{array}{l}+0.28 \\
+0.29 \\
+0.30 \\
+0.30 \\
+0.35\end{array}$ & $\begin{array}{l}173.41 \\
173.72 \\
174.03 \\
174.32 \\
174.56\end{array}$ & $\begin{array}{l}-0.19 \\
-0.18 \\
-0.17 \\
-0.15 \\
-0.15\end{array}$ & $\begin{array}{l}173.68 \\
174.00 \\
174.28 \\
174.56 \\
174.85\end{array}$ & $\begin{array}{l}-0.03 \\
-0.02 \\
-0.02 \\
-0.02 \\
+0.01\end{array}$ \\
\hline III & $\begin{array}{l}1700 \\
1750 \\
1800 \\
1850 \\
1900\end{array}$ & $\begin{array}{l}174.18 \\
174.52 \\
174.80 \\
175.06 \\
175.36\end{array}$ & $\begin{array}{l}+0.08 \\
+0.11 \\
+0.12 \\
+0.13 \\
+0.17\end{array}$ & $\begin{array}{l}174.18 \\
174.51 \\
174.81 \\
175.07 \\
175.30\end{array}$ & $\begin{array}{l}+0.08 \\
+0.11 \\
+0.13 \\
+0.14 \\
+0.14\end{array}$ & $\begin{array}{l}173.51 \\
173.79 \\
174.13 \\
174.45 \\
174.62\end{array}$ & $\begin{array}{l}-0.30 \\
-0.31 \\
-0.26 \\
-0.22 \\
-0.25\end{array}$ & $\begin{array}{l}173.72 \\
174.02 \\
174.29 \\
174.54 \\
174.77\end{array}$ & $\begin{array}{l}-0.18 \\
-0.17 \\
-0.17 \\
-0.17 \\
-0.16\end{array}$ \\
\hline
\end{tabular}

${ }^{a}$ The quantity $\Delta \rho$ is percentage deviation of the individual results from the smooth function represented by equation (2).

TABLE A-3. Experimental results on hemispherical total emittance of the titanium alloy

\begin{tabular}{c|c|r}
\hline \hline \multirow{2}{*}{ Specimen } & $\begin{array}{c}T \\
(\mathrm{~K})\end{array}$ \\
\hline \multirow{2}{*}{1} & 1714 & $\boldsymbol{\epsilon}$ \\
\hline \multirow{2}{*}{2} & 1896 & 0.394 \\
& 1705 & .388 \\
\hline \multirow{2}{*}{3} & 1885 & 0.380 \\
\multirow{2}{*}{4} & 1706 & .376 \\
\hline & 1879 & .392 \\
\hline
\end{tabular}

\section{References}

[1] Cezairliyan, A., Design and Operational Characteristics of a High-Speed (Millisecond) System for the Measurement of Thermophysical Properties at High Temperatures, J. Res. Nat. Bur. Stand. (U.S.), 75C (Eng. and Instr.), No. 1, 7-18 (Jan.-Mar. 1971).
[2] Cezairliyan, A., Morse, M. S., Berman, H. A., and Beckett, C. W., High-Speed (Subsecond) Measurement of Heat Capacity, Electrical Resistivity, and Thermal Radiation Properties of Molybdenum in the Range 1900 to 2800 K, J. Res., Nat. Bur. Stand. (U.S.), 74A, (Phys. and Chem.), No. 1, 65-92 (Jan.-Feb.1970).

[3] International Practical Temperature Scale of 1968, Metrologia 5, 35 (1969).

[4] Ziegler, W. T., and Mullins, J. C., Specific Heat of Titanium Alloys, Georgia Inst. Tech., Final Report, Project No. A504 (1961).

[5] Deem, H. W., Wood, W. D., and Lucks, C. F., The Relationship Between Electrical and Thermal Conductivities of Titanium Alloys, Trans. Met. Soc. AIME, 212, 520 (1958).

[6] Ermolaev, B. I., Thermal Conductivity and Electrical Conductivity of Materials Based on Titanium and Its Alloys from 20-80 to $1000 \mathrm{~K}$, Metal Science and Heat Treatment, 16, 1049 (1974).

[7] de L'Estoile, H., and Rosenthal, L., Advisory Group for Aeronautical Research and Development, Paris, France, AGARD-211 N6321549, (1958).

[8] Betz, H. T., Olson, O. H., Schurin, B. D., and Morris, J. C., WADCTR-56-222 (Part 2), (1957) (AD202493).

[9] Charlesworth, J. H., Melting Points of Metallic Elements and Selected Compounds, Air Force Materials Laboratory Report, TR-70-137 (1970).

(Paper 81A2\&3-927) 